\title{
Editorial: What's the question?
}

Market research has traditionally been used to inform, inspire and guide the search for and development of brand and communication ideas. But over the last year or so, there has been an opinion voiced from a section of the account planning community that there is little, or at least less, value in talking with consumers in this way. ${ }^{1}$

I have to admit that I bristled when first exposed to this view; how could these people have the audacity to believe that they could pronounce on what was best for a brand! Surely the recommendations of account planners should always be underpinned by impartial evidence as provided by market research.

But, on further consideration, I have come to believe that there is an important thought underlying this apparently anarchic view. That is, if you do not raise the right questions in the first place, then no amount of consumer research will appropriately guide your strategic thinking. And even if you do raise the right questions in terms of content, they then still need to be expressed in a form that the consumer is capable of answering.

So, the research skill-set required of today's generation of brand custodians and their consultants is more than knowledge gathering, analysis and interpretation. They must also be superb at interrogation. Indeed, this is likely to become the most valued skill of all in contributing to the development of the brand vision. Without sufficient expertise in raising the appropriate questions in both content and form, traditional re- search methodologies and techniques run the risk of letting us down. In which case, we might well conclude that there is little point in talking to consumers at all. A half-trained fighter is arguably more vulnerable than the untrained man competing on instinct alone.

\section{INFORMATION OVERLOAD}

In the past I would often find solutions by gathering all the available information about a subject, immersing myself in it for a while, and then emerging with a recommendation that would hopefully solve the problem at hand; what I have come to term as 'cauldronthinking'. It used to be a pretty effective way of finding an insight, idea or proposition that would powerfully drive a brand. The luxury was that the physical and financial limitations in data collection, provision and dissemination restricted the amount of information available; it was possible to complete the task as defined.

Heaven help you if you ask a brand owner to arrange for you to be briefed on everything they know about the market, brands and consumer these days! Truckloads of information arrive in your offices and the email server is severely challenged. Then there's the need to understand the broader perspective of social, economic and political trends, plus the requirement to compare and contrast with another, say, 40 markets. The amount of potentially useful data available today goes far beyond our available time and interpretative capacity. To find new ideas 
we must seek to raise stimulating hypotheses from our initial core data and set out on a progressive path, proving and disproving with evidence, developing and refining our ideas as we go; I call this the 'thinking journey'.

\section{THE THINKING JOURNEY}

Nowadays I am forced to work predominantly in this way. It is helped in that it is now possible to find out the answer to just about anything. Indeed, we are seeing the emergence of solution brands to help with exactly that (eg askjeeves.com, yahoo.com, whatsonwhen.com).

The focus does not need to be so concentrated on data-gathering anymore; we can pick that up on the way. The focus must be on the thinking and pinpointing of those key questions, that when you do answer them will unlock the potential of your brand by revealing new, relevant and intriguing ideas. As the ideas emerge, they will often connect with each other and illuminate the way to even more exciting options.

\section{THE SEARCH}

As custodians, we seek to differentiate the brands in our care in ways that appeal to consumers. Successful brands take ownership of and act out a specific, relevant offer, idea or even myth. ${ }^{2}$ They will build a sustainable relationship with their customers, delivering both tangible and emotional benefits, thereby generating selection, sales and loyalty. The focus of the search is therefore for the differentiating and relevant brand idea that connects with the consumer and builds a relationship.

\section{OUR WORLD}

Brand management has been a recognised profession for decades. There is plenty experience and tried and tested approaches in the marketplace. So what has changed?

It sounds a cliché to say that we (and our consumers) are living in times of rapid and significant change - it seems that every paper on branding in the last 30 years has made this observation! But there now seems to be more change than ever, which creates a constantly changing canvas on which we seek to build positive and sustainable consumer-brand relationships.

It is not the purpose of this paper to provide a comprehensive analysis of the changing world, but by way of example, here are some issues that have preoccupied me lately in my thinking journeys.

There continues to be increasing competition for time; our time as managers and the customers' time as consumers. There are so many opportunities in the world today; how does one choose what to do - which activities win and which lose out? How do consumers balance eating and drinking with health and sport; balance the books financially; balance the time between work and play; allocate time to each member of their family and friends; balance being with doing? What are the trade-offs and how are they resolved?

Media consumption continues to fragment; on any single evening the satellite television viewer will have hundreds of programmes to choose from. How do they make their choices? When does inertia set in and for whom? What effect does fragmented viewing have on the sense of belonging and the desire for collective 
shared experiences? How can brands reach their audiences effectively in the future; what modes of communication will dominate; for whom; how will they all pull together?

Market sectors have become more cluttered and overlapping. Choosing a yoghurt has become a paralysing experience as the consumer is faced with a massive array of product types, formats and flavours, let alone brands. Keywords like 'organic' help cut through the crowd; what will the next ones be? Brands appear in unexpected categories, but the consumer learns to accept them in strange places; perceived 'soft' values create a sense of expertise and have come to dominate over traditionally associated functional capabilities blurring the boundaries between them.

The digital revolution has further changed the rules of the game as businesses and consumers embrace the internet, laptop, mobile phone and now WAP technology. Customisation of information is increasingly available and readily accessible; a personalised world where no two people will be receiving the same messages.

In the hopelessly cluttered web marketplace, trusted brands are more important than ever, and companies must never undermine that trust. $^{3}$

David Siege ${ }^{4}$ describes a new definition of loyalty where e-consumers are loyal not to the brand per se but to other customers and the employees with whom they have established a relationship. What effect will this have on the development and management of brand tribes and brand communities? ${ }^{5}$

Kevin Kelly ${ }^{6}$ identifies three key implications of the so-called new economy; globality, the favouring of intangibles (such as ideas, information and relationships) and that things are intensely interlinked. We now have the opportunity and the capability to connect things together in previously unimagined ways; commerce, behaviour, products, ideas and so on it is up to us to investigate the options.

John $\mathrm{Kao}^{7}$ proposes that following the agricultural, industrial and informational eras of economic activity, we are now in the era of the creative. To quote him: '. . now business seeks a new advantage - delicate and dangerous, and absolutely vital — the creativity advantage'.

The stakes have been raised: the gauntlet thrown down. In our search for differentiation and creative advantage, and not just competitive advantage, ideas are not only the responsibility of the so-called creative advertising people. Everyone involved with the brand needs to open up their thinking, and that includes how we manage the input of the consumer.

'A chieftain who asks the wrong questions always hears the wrong answers."

\section{A QUESTIONING APPROACH}

It is demanding both of yourself and others to be constantly questioning. We are quickly worn down by a child going through their 'why' phase.

"'I have answered three questions, and that
is enough," said his father: "don't give
yourself airs! Do you think I can listen all
day to such stuff? Be off, or I'll kick you
downstairs!",
Lewis Carroll, 'Alice in Wonderland' If, as John Kao proposes, we are in the era of creativity, we should be utilising 
questioning techniques that bring out the creative child in us. Ignore the father; get into Wonderland and keep on asking! Or perhaps we'll get to those elusive big ideas by drilling down deeper and being more poetic.

'The poet is the unsatisfied child who dares to ask the difficult question which arises from the schoolmaster's answer to his simple question, and then the still more difficult question that arises from that.'

Robert Graves, 'The White Goddess'

We can start our thinking journey with the simple question list of who, what, where, when, why and how, and then expand from there. Edward de Bono's 'Six Thinking Hats' is an example of a next-level valuable framework and there are many others. The specific question sets will, of course, differ brand by brand.

A major challenge these days is the search for consumer insights on which to base brand ideas and brand differentiation. The search for insights depends on thoughtful and tailored questioning. I have heard of databanks being set up in organisations with the purpose of storing 'insights' for future use across a series of brands. Personally I find this practice incomprehensible as, in my experience, an insight will only be powerful if it has been developed apropos a specific consumer-brand relationship.

Brands in different situations will again require different questions. In 'Eating the Big Fish', Adam Morgan ${ }^{10}$ has developed an approach specifically designed for working with 'challenger brands'. Dominating brands also need their own overall interrogation set, plus specific questions for the brand at hand.
Another example is questioning how far the past and the present will be of importance in planning a brand's future. For some, there is significant nourishment to be gained from the past; childhood and collective memory, heritage and so on — well worth investigating. The past will not be of relevance to all brands; some would do best to abandon it and move swiftly forward. The new dot.com brands present a very different set of challenges as they seek to build rapidly a relationship with the consumer, quickly creating a different sort of past.

A questioning approach is not a new way of thinking; it's just that there isn't enough of it going on. 'What we always do in this company' will avoid rocking the boat, but it probably will not highlight the very best way forward, nor will 'what worked for the other brand last time'. We need to determine the goals and the issues, then set off on the thinking journey, engaging with the likely issues behind the issues, the questions behind the questions, following up leads and gathering our answers and clues. Only then can we build up the proper understanding to make confident interpretative leaps and sound recommendations for the brands in our care and draw up the map for their future.

\section{IMPLICATIONS}

Classic research approaches will be appropriate for answering many of our questions. But not all of them. There is a limit to what consumers can identify and express in a research situation. They can tell you a lot about their past and present behaviour and attitudes, need, wants and desires, but only a 
limited amount about how it will be in the future. But the more appropriately you form the question, the more you can discover.

We cannot expect too much if we do not fully prepare; respondents (and executive teams) may well not be able, for example, to come up with fantastic ideas for new products when working only from their own experiences. We need to first concentrate on defining the underlying questions and then get guidance on them - not what new shoes we should be making, but what questions we should be raising and exploring about, say, fabrics, weather trends, people's weight, chiropody, recycling and so on.

Finding the path for the future of the brand requires a different sort of brief. The classic researcher, brand manager or even planner might not always be the most appropriate investigator. The pursuit or journey might be better handled by a new or hybrid-type. Perhaps someone who also brings along experience in some or all of psychology, anthropology, the arts, media, creative thinking, communications and facilitation; who understands research but can also guide the thinking journey, identifying and developing ideas as they go. Or by creating a special team, perhaps comprised of a mix of nationalities. A more classic research approach can then be utilised for subsequent validation and diagnosis.

There is nothing wrong with the research techniques that are used today for data gathering, analysis and interpretation. They are tried and tested and each have valuable roles. But we cannot just apply an assortment of them on an issue in the vain hope that one of them will deliver the holy grail; the big idea for the brand or the stunning consumer insight. The groundwork needs to be done upfront, raising the questions for the thinking journey. Brand custodians must seek to explore beyond the closed environment of the organisation, raising the hypotheses, agreeing the most appropriate questions and then working out how to form them for investigation.

So what's the question? It's about raising the questions. Defining bespoke thinking journeys for the brand is likely to uncover successful ideas and opportunities. Hopefully none of the brands in your care will then ever be forced to ask: 'To be or not to be?'.

\section{Linda Caller Editorial Board}

\section{References}

(1) Account Planning Group meetings and debates 1999-2000.

(2) Nazerali, Sanjay (2000) 'Brand mythology', The Journal of Brand Management, Volume 7, Number 6, pp. 405-11.

(3) Schwartz, Evan I. (1999) 'Digital Darwinism', Penguin, London.

(4) Siegel, David (1999) 'Futurize your enterprise', John Wiley \& Sons, New York.

(5) Caller, Linda and Byfield, Sheila (1995) 'Managing transnational brands in times of change', reprinted in (1999) Monograph No. 8 'International marketing research', ESOMAR, Amsterdam.

(6) Kelly, Kevin (1998) 'New rules for the new economy', Fourth Estate, London.

(7) Kao, John (1996) 'Jamming: the art and discipline of business creativity', HarperCollins Business, London.

(8) Roberts, Wess (1989) 'Leadership secrets of Attila the Hun', Transworld, London.

(9) De Bono, Edward (1985) 'Six Thinking Hats', Penguin, London.

(10) Morgan, Adam (1999) 'Eating the big fish', John Wiley \& Sons, New York. 